\title{
A randomized phase II clinical trial of dendritic cell vaccination following complete resection of colon cancer liver metastasis
}

\author{
Javier Rodriguez', Eduardo Castañón'1, Jose Luis Perez-Gracia 1,4,5, Inmaculada Rodriguez ${ }^{1,4}$, Antonio Viudez ${ }^{2,5}$, \\ Carlos Alfaro ${ }^{1,4}$, Carmen Oñate', Guiomar Perez ${ }^{1}$, Fernando Rotellar ${ }^{1}$, Susana Inogés ${ }^{1,5}$, \\ Ascensión López-Diaz de Cerio ${ }^{1,5}$, Leyre Resano ${ }^{1}$, Mariano Ponz-Sarvise ${ }^{1,3,5}$, Maria E. Rodriguez-Ruiz 1,3,4, \\ Ana Chopitea', Ruth Vera ${ }^{2,5}$ and Ignacio Melero $1,3,4,5,6^{*}$
}

\begin{abstract}
Surgically resectable synchronic and metachronic liver metastases of colon cancer have high risk of relapse in spite of standard-of-care neoadjuvant and adjuvant chemotherapy regimens. Dendritic cell vaccines loaded with autologous tumor lysates were tested for their potential to avoid or delay disease relapses (NCT01348256). Patients with surgically amenable liver metastasis of colon adenocarcinoma $(n=19)$ were included and underwent neoadjuvant chemotherapy, surgery and adjuvant chemotherapy. Fifteen patients with disease-free resection margins were randomized 1:1 to receive two courses of four daily doses of dendritic cell intradermal vaccinations versus observation. The trial had been originally designed to include 56 patients but was curtailed due to budgetary restrictions. Follow-up of the patients indicates a clear tendency to fewer and later relapses in the vaccine arm (median disease free survival-DFS-) 25.26 months, 95\% Cl 8. 74-n.r) versus observation arm (median DFS 9.53 months, 95\% Cl 5.32-18.88).
\end{abstract}

Keywords: Dendritic cell, Colon cancer, Vaccine, Relapse prevention, Randomized clinical trial

\section{Introduction}

In spite of high expectations, cancer vaccines have found little applicability in oncology clinical practice [1]. It is likely that vaccines will be more efficacious at preventing relapse in patients with minimal residual disease status as opposed to advanced cases with bulky and immunosuppressive disease $[1,2]$.

Dendritic cell vaccines harness the antigen-presenting functions of these leukocyte subsets to induce antitumor CD8 and CD4 T cell responses [3]. The only exception of a FDA-approved cancer vaccine is a monocyte-derived dendritic cell product pulsed with a prostate serum antigen

\footnotetext{
* Correspondence: imelero@unav.es

Javier Rodriguez and Eduardo Castañón are equal contribution.

Ruth Vera equally share credit for senior authorship.

${ }^{1}$ Clinica Universidad de Navarra, Avenida Pio XII, 36, 31008 Pamplona, Spain

${ }^{3}$ Centro de Investigacion Medica Aplicada, CIMA, Avenida Pio XII, 36, 31008

Pamplona, Spain

Full list of author information is available at the end of the article
}

chimeric protein (Sipuleucel, Provenge) which was approved based on overall survival benefit $[4,5]$ for castration resistant metastatic prostate cancer. The nature of the antigen is likely to be important with current preference for antigens encoded by non-synonymous mutations or other gene alterations in the tumor genome [6]. Presentation of such antigens can be attained by pulsing defined peptide sequences following their genomic identification [7] or transfecting total tumor mRNA into the DCs [8]. A simpler alternative is the use of autologous tumor lysates to load the $\mathrm{DC}$, which are known to immunize to at least to some extent to those relevant neoantigens [9-13].

We have developed a clinical-grade product based on autologous CD14+ monocytes differentiated to DC by means of 7-day cultures in the presence of GM-CSF and IL-4. Such cultures are incubated with autologous tumor lysate and activated by a cocktail of agents combining TNF $\alpha$, poly-ICLC (Hiltonol ${ }^{\mathrm{tm}}$ ) and IFN $\alpha$ [12]. We have

(C) The Author(s). 2018 Open Access This article is distributed under the terms of the Creative Commons Attribution 4.0 International License (http://creativecommons.org/licenses/by/4.0/), which permits unrestricted use, distribution, and 
previously reported immunogenicity and safety of the approach [2], that showed intriguing long relapse-free survival in a series of resected glioblastoma cases [14].

Colon cancer frequently metastasize to the liver and in some cases, rescue surgery is feasible [15]. Various studies recommend neoadjuvant and adjuvant chemotherapy to reduce relapse risk [16-19] that in the best series still remains over $50-60 \%$. Previous attempts have been made to use cancer vaccines to prevent relapse, including positive trials with Bacillus Calmette Guerin (BCG) mixed with autologous irradiated tumor cells from the resection specimen. This preventive treatment to avoid relapse was effective in stage II colon carcinoma but not in stage III or IV [20].

In this disease scenario of surgically amenable colon cancer with liver metastases, minimal residual disease is expected following surgery plus chemotherapy. We have tested our previously reported DC formulations loaded with autologous tumor lysates [12] in a randomized fashion. Even if the trial had to be halted with only 15 randomized patients, our follow-up observation strongly suggests a beneficial effect of the vaccination scheme on disease-free survival (DFS).

\section{Patients and methods}

\section{Patient selection and treatment}

This is an open label randomized phase II trial (Study With Dendritic Cell Immunotherapy in Resected Hepatic Metastasis of Colorectal Carcinoma registered on May 11th 2011 in https://www.clinicaltrials.gov/ct2/ show/NCT01348256) evaluating the efficacy of dendritic cell vaccination versus observation in patients with potentially resectable liver metastases from colon cancer who underwent a complete scheme of neoadjuvant chemotherapy, surgery and adjuvant chemotherapy. The investigative product dossier (IMPD), the clinical trial protocol were approved by the Agencia Española del Medicamento y productos saninatios (AEMPS). The clinical trial protocol and informed consent forms were approved by the regional ethics committee.

General inclusion criteria comprised patients diagnosed with stage IV colon cancer with liver metastases, ECOG $<=2$, hemoglobin $>9 \mathrm{~g} / \mathrm{dl}$, platelets $>50.000 / \mathrm{mm} 3$, leucocytes $>3000 / \mathrm{mm} 3$, Bilirubin $<5 \times$ ULN, ASAT and ALAT $<5 \times$ ULN, Creatinine $<2 \times$ ULN and negativity to HBV, HCV and HIV. Patients should have had tumor sample available in order to produce autologous tumor lysate for DC loading. Exclusion criteria included active infection or conditions which could jeopardize patient's safety, concurrent treatment for the oncological disease (either approved or investigational), active CNS metastases, second malignancies excluding squamous or basal cell carcinoma, cervical carcinoma or other tumors treated radically within the previous 3 years, pregnant or breastfeeding women and patients receiving immunosuppressive agents.

Patients should have undergone a scheme of neoadjuvant chemotherapy (including standard 5FU + platinum based schemes), followed by surgery of liver metastases and the primary tumor (if existing) as well as an adjuvant chemotherapy scheme (including $5 \mathrm{FU}+$ platinum based regimens).

\section{Dendritic cell preparation and vaccination}

In the surgical procedure, enough malignant tissue material had to be retrieved to prepare tumor lysate by freeze/thaw with a first cycle of heating at $90{ }^{\circ} \mathrm{C}$ for five minutes to favor protein aggregation and inactivate proteases. In the DC treatment group, patients underwent 2-3 volume leukoapheresis and CD14+ monocytes were selected by clinical-grade immunomagnetic selection using clinicimacs technology (Miltenyi biotec). As previously described [2], monocytes were cultured in cell-culture flasks $(175 \mathrm{~cm} 2$; Corning, Sigma- Aldrich, St. Louis, MO) for 7 days in AIM-V serum-free media (Life Technologies-BRL, Gaithersburg, MD) supplemented with GM-CSF $(1000 \mathrm{U} / \mathrm{ml}$; Leukine, Berlex, Richmond, CA) and IL-4 (500 U/ml; R\&D Systems, Minneapolis, MN). With this protocol, at least over $90 \% \mathrm{CD} 11 \mathrm{c}$ + viable dendritic cells were obtained in all cases.

Tumor lysates were generated from needle-core tumor biopsies or surgical samples. Tumor tissue disruption was performed with the GentleMacs dissociator device (Miltenyi Biotec), followed by the freezing/thawing and irradiation procedures, to be be subsequently cryopreserved at $220^{\circ} \mathrm{C}$ until used.

DC cultures were pulsed with lysate at 100 micrograms of protein $/ \mathrm{mL}$ and two hours later induced to mature for $24 \mathrm{~h}$ with polyICLC (Hiltonol) $1 \mu \mathrm{g} / \mathrm{mL}, \mathrm{TNF} \alpha 50 \mathrm{ng} / \mathrm{ml}$ (Boehringer Ingelheim, Ingelheim, Germany) and IFNa (1000 IU/ml; Schering-Plough, Kenilworth, NJ). Cells were immediately used or frozen for subsequent administrations to patients.

Freezing and thawing of matured and Ag-loaded DC were performed, as described previously [11]. DC were slowly frozen in autologous serum with $5 \% \mathrm{v} / \mathrm{v}$ DMSO by using a computer-assisted step down freezer (CM-25; Carburos Metalicos). The first two treatments were performed with cultured cells without any previous freezing step, whereas the rest of the treatments were prepared with thawed DC.

DC activation/maturation was confirmed by FACS assessing increases in the immunofluorescence of CD80, CD86, and HLA-DR. Immediately after thawing, cell viability was assessed by trypan blue exclusion ranging from 76 to $98 \%$. Flow cytometry analysis was performed at day 7 using FACScan (BD Biosciences, San Diego, CA). Release criteria for DC included 75\% HLA-DR+ and CD11c bright and 
negative tests for microbial contamination. All the vaccines have passed the release criteria. Repeated Vaccination was performed by intradermal injection given bilaterally alternating the anterior upper thigh regions of the patients.

\section{Flow cytometry}

For DC phenotype characterization, the following Abs were used: CD11c (clone 3.9 from Biolegend), HLA-DR (clone G46-6 from Biolegend), CD80 (clone L307.4 from Pharmingen), CD86 (clone 2331(FUN-1) from Pharmingen) and CD14 (clone M5E2 from Biolegend). Samples were analyzed using a FACSCanto flow cytometer (BD Biosciences).

\section{Cytokine determinations}

Simultaneous measurement of TNF- $\alpha$, IL-1 $\beta$, IL- 6 , IL-8, IL-10 and IL-12p70 in the supernatant from the mature DCs was analyzed by microparticle-based flow cytometry (Cytometric Bead Array) according to the manufacturer's instructions (BD Biosciences, San Jose, CA).

\section{IFNY ELISPOT}

Human IFNY ELISPOT PRO Kit (MABTECH) was used according to manufacturer instructions. Plates were blocked with RPMI 1640 supplemented with 10\% FBS for $1 \mathrm{~h}$ at $37^{\circ} \mathrm{C}$. The medium was aspirated, and effector cells $\left(2.5 \times 10^{5}\right)$ were seeded in triplicates in RPMI 1640 with $10 \%$ heat-inactivated FCS. PBMC isolated before treatment and at day +30 post treatment, were used as effector cells. Stimulator cells were autologous mature DC loaded with tumor lysates $(50-250 \mu \mathrm{g} / \mathrm{ml})$. DC had been matured with TNF- $\alpha(50 \mathrm{ng} / \mathrm{ml})$, IFN- $\alpha(1000 \mathrm{U} / \mathrm{ml})$, and poly(ICLC) $(20 \mu \mathrm{g} / \mathrm{ml})$ for $48 \mathrm{~h}$ in AIM-V medium (BioWhittaker Lonza). DCs $\left(5 \times 10^{4}\right)$ were cultured with the effector cells. Negative control wells contained equally seeded with unloaded DC and without DC. Positive controls were standard SEB 1:100 dilution (SIGMA). Cells were incubated at $37{ }^{\circ} \mathrm{C}$ in $5 \% \mathrm{CO}_{2}$ in a water-saturated atmosphere. After a culture period of $36 \mathrm{~h}$, cells were removed by six washings with PBS/0.05\% and ELISPOT was developed acording to manufacturer instructions and spots per well were automatically counted with automated immunospot counter (CTL).

\section{Statistical considerations}

Different variables were collected including tumor size $(\mathrm{pT})$, nodes invasion $(\mathrm{pN})$, type of tumor margins (R0 vs R1/R2), Nagashima score, which categorizes patients regarding their suitability for liver resection taking into account number of hepatic metastatic tumors, liver metastatic tumors larger than $5 \mathrm{~cm}$ in diameter, resectable extra- hepatic distant metastases, regional lymph node metastases and serosal invasion of primary colorectal cancers [21], Fong score (which measures the risk of relapse after hepatic resection based on node-positive primary tumor, disease-free interval from primary to metastases $<12$ months, number of hepatic lesions $>1$, largest hepatic tumor $>5 \mathrm{~cm}$ and carcinoembryonic antigen level $>200 \mathrm{ng} / \mathrm{ml}$ ) [22]. Disease-free survival was measured as the time from surgery to relapse, death or loss of follow-up. Survival curves were compared based on the Kaplan Meier estimates [23]. A log rank test was used in order to calculate the difference between curves. Median follow up was calculated based on the inverse Kaplan Meier method [24]. All calculations were performed with STATA v.14 statistical package (StataCorp 2015).

\section{Results}

We have previously reported that a cell therapy product consisting of monocyte-derived DC loaded with heat-treated autologous tumor lysate and matured with a cocktail of poly-ICLC, TNF $\alpha$ and IFN $\alpha$ was immunogenic [11].

An unmet clinical setting in which vaccines would be very useful is the prevention of relapse following potentially curative resections of colon adenocarcinoma liver metastases. A randomized clinical was designed to address a putative beneficial effect of this treatment versus standard-of-care at our institutions.

The original design of this academically sponsored trial (NCT01348256) included 56 patients but budget restrictions forced an early termination of recruitment, when only 19 patients had signed informed consent.

As indicated in Fig. 1a, three of the patients were excluded for evaluation due to positive resection margins (>R0) following neoadjuvant chemotherapy and surgery. One patient withdrew informed consent after neoadjuvant treatment, and thus was not randomized. Neoadjuvant chemotherapy consisted of standard chemotherapy 5-FU-based cycles (Table 1) .

Surgery included lobe or segmental liver resections as required. Once adjuvant chemotherapy was over, patients were randomized to receive dendritic cell vaccinations or observation (Fig. 1a and b).

A regimen of two cycles of four daily intradermal vaccines given bilaterally in the two upper thigh regions was followed as described [3] to maximize acute immunization.

Table 1 reflects the characteristics of the 15 patients who were in excellent performance status. Remarkably, the observation group was unbalanced with more favorable cases as depicted by risk scales (Nagashima and Fong scores). Indeed, the vaccination group had five patients with high Nagashima risk, while there was none in the observation group. All cases were diagnosed as metastatic carcinoma of the colon with more serum expression of CEA in the cases included in the vaccine arm (Table 1). Importantly, neoadjuvant chemotherapy 


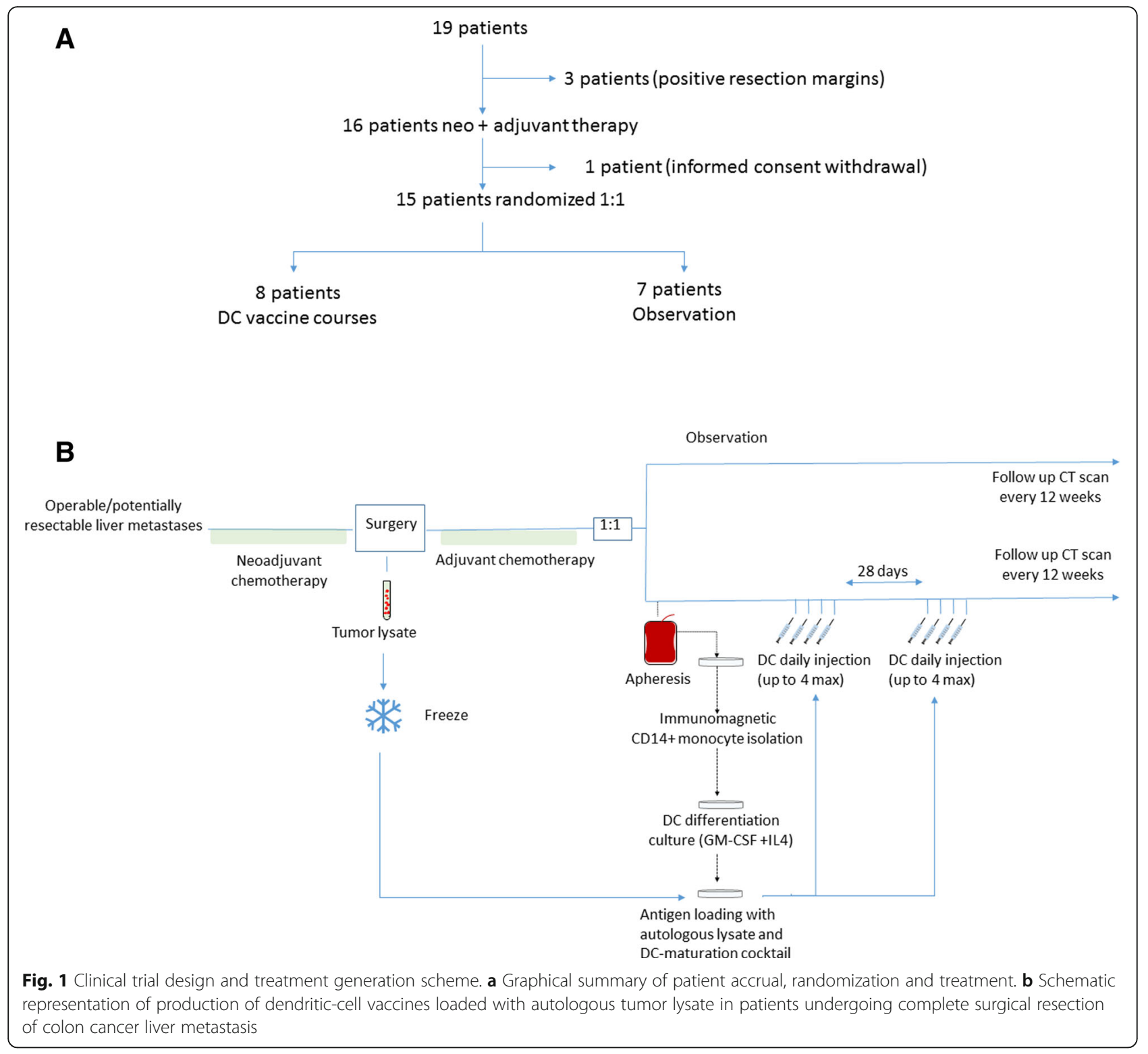

exposure was similar in the two arms. K-RAS mutation status was well balanced between treatment and observation arms (Table 1 ).

Follow-up was performed every 12 weeks (range 1114 weeks) ever since surgical treatment by contrast abdominal CT scans.

Treatment with DC was safe and only grade 1 treatment-attributable side effects were recorded. At median duration of follow-up of 42.58 months, disease free survival (DFS) appeared different in the two groups, as seen in the Kaplan-Meier curves in Fig. 2. Even though numbers of patients are small, a log-rank test estimated a probability of 0.067 and the median disease-free survival was 25.26 months in the vaccination arm as compared to 9.53 months in the observation arm.
In the vaccine arm four patients have not relapsed while four of them eventually relapsed. It is of note that there were three MSI-High cases in the vaccination arm while there was none in the observation arm (Table 1). However, two of the MSI-High cases have relapsed while one remains disease-free indicating that MSI-High status does not provide protection at the metastatic stage.

We monitored dendritic cell vaccine maturation in terms of cytokine secretion to the culture supernatant and surface expression of maturation markers (Additional file 1). DC products were highly mature and produced large amounts of Interleukin-12. As can be seen in Additional file 1, there was a tendency to larger Interleukin- 8 production by DC from relapsed cases and intriguingly a higher intensity of surface expression of CD11c. However, the small number 
Table 1 Patient population description

\begin{tabular}{|c|c|c|}
\hline & $\begin{array}{l}\text { Dendritics cell vaccine } \\
(n=8)\end{array}$ & $\begin{array}{l}\text { Observation } \\
(n=7)\end{array}$ \\
\hline Age (mean, Cl 95\%) & $58.75(52.25-65.25)$ & $56.29(52.92-69.66)$ \\
\hline \multicolumn{3}{|l|}{$\operatorname{Sex}(\%)$} \\
\hline Male & $50 \%$ & $62.5 \%$ \\
\hline Female & $50 \%$ & $37.5 \%$ \\
\hline ECOG (median, range) & $0(0-1)$ & $0(0-1)$ \\
\hline ESMO (median, range) & $1(0-1)$ & $0(0-1)$ \\
\hline Köhne (median, range) & $0(0-1)$ & $0(0)$ \\
\hline \multicolumn{3}{|l|}{ Nagashima score (\%) } \\
\hline Low risk & $0 \%$ & $50 \%$ \\
\hline Moderate risk & $33.33 \%$ & $50 \%$ \\
\hline High risk & $66.67 \%$ & $0 \%$ \\
\hline \multicolumn{3}{|l|}{ Fong score (\%) } \\
\hline Low risk & $50 \%$ & $57.14 \%$ \\
\hline High risk & $50 \%$ & $42.86 \%$ \\
\hline \multicolumn{3}{|l|}{ Histology (\%) } \\
\hline Adenocarcinoma & $87.5 \%$ & $100 \%$ \\
\hline Mucinous & $12.5 \%$ & $0 \%$ \\
\hline \multicolumn{3}{|l|}{ CEA (\%) } \\
\hline$<200 \mathrm{ng} / \mathrm{ml}$ & $50 \%$ & $85.7 \%$ \\
\hline$>200 \mathrm{ng} / \mathrm{ml}$ & $50 \%$ & $14.3 \%$ \\
\hline $\begin{array}{l}\text { Metastatic disease at } \\
\text { diagnosis }\end{array}$ & $87.5 \%$ & $57.4 \%$ \\
\hline $\begin{array}{l}\text { Neoadjuvant cycles } \\
\text { (mean, Cl 95\%) }\end{array}$ & $5.75(4.68-6.82)$ & $6.57(5.67-7.47)$ \\
\hline \multicolumn{3}{|l|}{ KRAS status } \\
\hline Mutant & $62.5 \%$ & $57.14 \%$ \\
\hline Wild type & $37.5 \%$ & $42.6 \%$ \\
\hline MSI status & $37.5 \%$ & $0 \%$ \\
\hline
\end{tabular}

of samples precludes solid conclusions beyond hypothesis generation. IFN $\gamma$-ELISPOT assays were conducted with pretreatment (time of leukoapheresis) and postreatment (4 weeks after the second treatment cycle) samples. As shown in Additional file 2, a clear increase in reactivity to tumor lysate-loaded DC was only seen in one of the non-relapsed cases. Marginal increases were observed in other cases (Additional file 2).

\section{Discussion}

Randomized evidence for efficacy of dendritic cell vaccination for cancer is yet missing. In cutaneous melanoma, DC pulsed with shared antigen peptides did not show evidence for benefit [25]. However, important adjuvant dendritic cell vaccination randomized trials for skin melanoma (NCT02993315) and uveal melanoma [26] are ongoing.

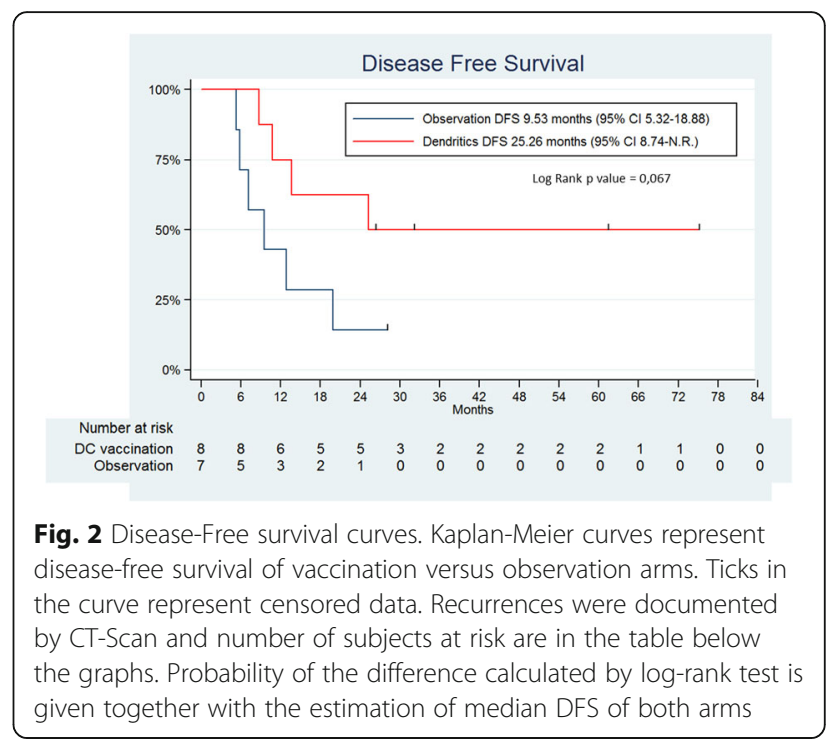

Our study chose resectable metastatic colon cancer because is an unmet clinical need in patients with potential minimal residual disease but at very high risk of relapse. Unfortunately, logistical/budgetary problems forced the trial to be halted with a short number of patients randomized to each of the two arms. However, these patients were kept in follow-up according to protocol and relapses evaluated as planned.

With all caveats due to patient sample size, current results are strongly supportive of a beneficial effect of DC vaccination that would warrant a confirmatory randomized clinical trial in a similar setting. It is worth mentioning that unbalanced presence of higher-risk of relapse patients (according to clinical scores) in the vaccination arm further supports the existence some degree of relapse-free survival benefit in the vaccinated arm. Reinforcing this notion, risk scales of relapse would have been predictive of higher probability of relapse in the vaccination arm. In this regard, there was also an unbalance in MSI-H status with three cases in the vaccination versus none in the observation arm. However, two of the MSI-H cases actually relapsed. This is important since MSI-H is related to less metastatic progression following surgery of the primary tumor [27] and higher antigenicity and more susceptibility to PD-1 blocking agents at metastatic stage [28]. However, once metastatic MSI-H patients show a similar progression pattern as non-MSI cases [29] as it is the case in our small series of patients.

An important question would be whether to go on with the same vaccination schedule or to provide some more boosting cycles of vaccination during the first and second year following surgery. The impression is that the vaccines may have prevented relapse in some patients, while in others vaccination might only have delayed relapse, thus advocating for extended boosting doses. 
The quality and maturation of the DC product was good in relapsed and non-relapsed cases following treatment, particularly showing prominent IL-12 production. A tendency to more IL-8 production and brighter surface expression of CD11c were noted in relapsed cases, a finding that warrants confirmatory research in ongoing and subsequent clinical studies.

Other points to be considered would be to add checkpoint inhibitors circa vaccination dates [30] and to monitor patients for immunization against neo-antigens by IFN $\gamma$ ELISPOT [12] or other techniques. Our series of IFN $\gamma$-ELISPOT assays is not sufficiently large to draw any conclusions but suggests interesting individual heterogeneity in the measurable response 4 weeks after the last vaccine.

There is recently published evidence supportive for checkpoint inhibitor immunotherapy approaches given in neoadjuvant schemes prior to surgery [31-33]. In our opinion, it makes sense to use anti PD-1 or PD-L1 mAbs prior to surgery as part of the neoadjuvant regimen. In this setting, postsurgical DC vaccinations would boost an already unleashed T-cell response. However, it must be taken into account that metastatic non-MSI colon cancer is mostly refractory to checkpoint inhibitors.

All considered, in spite of the reduced number of cases, results are very encouraging in favor the vaccination arm and indicative of the potential of DC vaccinations with autologous tumor antigens for patients with colon cancer liver metastasis amenable to complete surgical resections.

\section{Additional files}

Additional file 1: (PDF $1991 \mathrm{~kb}$ )

Additional file 2: (PDF $1084 \mathrm{~kb}$ )

\section{Acknowledgements}

We are grateful to the excellent work personal in the central clinical trial unit and cell therapy unit at Clinica Universidad de Navarra (CUN). Drs. Pedro Berraondo, Miguel F. Sanmamed, Juan J Lasarte, Pablo Sarobe, Jesus Prieto, Ignacio Gil-Bazo, and Joaquín Casariego are acknowledged for fruitful scientific discussions.

\section{Funding}

Financial support was from Instituto Carlos III (EC10-113 and TRA 007) and Fundacion BBVA.

\section{Availability of data and materials}

No series of series of data have been desposited in repositories. Clinical records are filed and kept at clinical Trial Unit in CUN.

\section{Authors' contributions}

JR: Recruited patients and supervised treatemtnt and supervised data base. EC Analyzed data and curated the clinical data base and wrote the draft of the paper, JL P-G Wrote clinical trial protocol and dealt with regulatory and funding issues, IR, performed and analyzed ELISPOT assays, AV recruited patients and followed up patients, CA and CO produced clinical grade dendritic cell vaccines and monitored quality control, GP technically assised GMP dendritic cell production and flow cytometry experiments, FR surgically operated patients, SI and A L-DdC supervised the cell therapy unit and worked standard operation procedures and quality control, LR was the clinical trial coordinator and nursing staff, MP and MERR are attending physicians at clinical trial unit who followed up patients and supervised treatments, AC recruited patients and supervised standard of care cases, RV codirected the study and recruited pateints, IM Coordinated and directed the study, obtained funding and wrote the paper. All authors read and approved the final manuscript.

\section{Ethics approval and consent to participate}

All patients provided informed consent approved as the clinical trial protocol by the CEIC of the local Government of Navarra (CEIC). The IMPD dossier and the clinical trial protocol were approved by Agencia Española del Medicamento y productos sanitarios (AEMPS). This was an investigator initiated clinical trial sponsored by UNAV and fulfills requirements by spanish law (Real Decreto 1090/2015).

\section{Consent for publication}

Informed consent included consent for publication and patients are coded and made anonym according to good clinical practices.

\section{Competing interests}

IM served as an advisor to BMS, Roche, AstraZeneca, Genmab, Alligator, Tusk, Bioncotech, Merck-Serono.

IM receives research grants from BMS, Roche and Alligator.

\section{Publisher's Note}

Springer Nature remains neutral with regard to jurisdictional claims in published maps and institutional affiliations.

\section{Author details}

${ }^{1}$ Clinica Universidad de Navarra, Avenida Pio XII, 36, 31008 Pamplona, Spain ${ }^{2}$ Complejo Hospitalario de Navarra, Avenida Irunlarrea 5, 31008 Pamplona, Spain. ${ }^{3}$ Centro de Investigacion Medica Aplicada, CIMA, Avenida Pio XII, 36, 31008 Pamplona, Spain. ${ }^{4}$ CIBERONC, Madrid, Spain. ${ }^{5}$ Instituto de investigación de Navarra, IDISNA, Pamplona, Spain. ${ }^{6}$ Pamplona, Spain.

Received: 30 April 2018 Accepted: 6 September 2018

Published online: 29 September 2018

\section{References}

1. Melero I, Gaudernack G, Gerritsen W, Huber C, Parmiani G, Scholl S, et al. Therapeutic vaccines for cancer: an overview of clinical trials. Nat Rev Clin Oncol. 2014;11(9):509-24.

2. Van Der Burg SH, Arens R, Ossendorp F, Van Hall T, Melief CJM. Vaccines for established cancer: overcoming the challenges posed by immune evasion. Nat Rev Cancer. 2016;16:219-33.

3. Bol KF, Schreibelt G, Gerritsen WR, IJM DV, Figdor CG. Dendritic cellbased immunotherapy: state of the art and beyond. Clin Cancer Res. 2016;22(8):1897-906.

4. Antonarakis ES, Kibel AS, Yu EY, Karsh LI, Elfiky A, Shore ND, et al. Sequencing of sipuleucel-T and androgen deprivation therapy in men with hormone-sensitive biochemically recurrent prostate cancer: a phase II randomized trial. Clin Cancer Res. 2017;23(10):2451-9.

5. Kantoff PW, Higano CS, Shore ND, Berger ER, Small EJ, Penson DF, et al. Sipuleucel-T immunotherapy for castration-resistant prostate Cancer. N Engl J Med. 2010;363(5):411-22.

6. Türeci Ö, Vormehr M, Diken M, Kreiter S, Huber C, Sahin U. Targeting the heterogeneity of cancer with individualized neoepitope vaccines. Clin Cancer Res. 2016:22(8):1885-96.

7. Carreno BM, Magrini V, Becker-Hapak M, Kaabinejadian S, Hundal J, Petti AA, et al. A dendritic cell vaccine increases the breadth and diversity of melanoma neoantigen-specific T cells. Science. 2015;348(6236):803-8.

8. Su Z, Dannull J, Heiser A, Yancey D, Pruitt S, Madden J, et al. Immunological and clinical responses in metastatic renal cancer patients vaccinated with tumor RNA-transfected dendritic cells. Cancer Res. 2003;63(9):2127-33.

9. Nestle FO, Alijagic S, Gilliet M, Sun Y, Grabbe S, Dummer R, et al. Vaccination of melanoma patients with peptide- or tumor lysate-pulsed dendritic cells. Nat Med. 1998:4(3):328-32.

10. Kandalaft $L E$, Chiang $C L$, Tanyi J, Motz G, Balint $K$, Mick R, et al. A phase I vaccine trial using dendritic cells pulsed with autologous oxidized lysate for recurrent ovarian cancer. J Transl Med. 2013;11:149. 
11. Alfaro C, Perez-Gracia JL, Suarez N, Rodriguez J, Fernandez de Sanmamed M, Sangro B, et al. Pilot clinical trial of type 1 dendritic cells loaded with autologous tumor lysates combined with GM-CSF, Pegylated IFN, and cyclophosphamide for metastatic Cancer patients. J Immunol. 2011;187(11): 6130-42.

12. Rodríguez-Ruiz ME, Perez-Gracia JL, Rodríguez I, Alfaro C, Oñate C, Pérez G, et al. Combined immunotherapy encompassing intratumoral poly-ICLC, dendritic-cell vaccination and radiotherapy in advanced cancer patients. Ann Oncol. 2018;29(5):1312-19.

13. Tanyi JL, Bobisse S, Ophir E, Tuyaerts S, Roberti A, Genolet R, et al. Personalized cancer vaccine effectively mobilizes antitumor $T$ cell immunity in ovarian cancer. Sci Transl Med. 2018;10(436):11.

14. Inogés S, Tejada S, Cerio AL-D, Pérez-Larraya JG, Espinós J, Idoate MA, et al. A phase II trial of autologous dendritic cell vaccination and radiochemotherapy following fluorescence-guided surgery in newly diagnosed glioblastoma patients. J Transl Med. 2017;15(1):104.

15. Brenner H, Kloor M, Pox CP. Colorectal cancer. In: The Lancet; 2014. p. 1490-502.

16. de Jong MC, Pulitano C, Ribero D, Strub J, Mentha G, Schulick RD, et al. Rates and patterns of recurrence following curative intent surgery for colorectal liver metastasis: an international multi-institutional analysis of 1669 patients. Ann Surg. 2009;250(3):440-8.

17. Goldberg RM, Fleming TR, Tangen CM, Moertel CG, Macdonald JS, Haller DG, et al. Surgery for recurrent colon cancer: strategies for identifying resectable recurrence and success rates after resection. Ann Intern Med. 1998;129(1):27-35.

18. Spolverato G, Pawlik TM. Liver-directed therapies: surgical approaches, alone and in combination with other interventions. Am Soc Clin Oncol Educ B. 2014;34:101-10

19. Kusano M, Honda M, Okabayashi K, Akimaru K, Kino S, Tsuji Y, et al. Randomized controlled phase III study comparing hepatic arterial infusion with systemic chemotherapy after curative resection for liver metastasis of colorectal carcinoma: JFMC 29-0003. J Cancer Res Ther. 2017;13(1):84

20. Vermorken JB, Claessen AM, van Tinteren H, Gall HE, Ezinga R, Meijer S, et al. Active specific immunotherapy for stage II and stage III human colon cancer: a randomised trial. Lancet. 1999;353(9150):345-50.

21. Nagashima I, Takada T, Okinaga K, Nagawa H. A scoring system for the assessment of the risk of mortality after partial hepatectomy in patients with chronic liver dysfunction. J Hepato-Biliary-Pancreat Surg. 2005;12(1):44-8.

22. Fong Y, Fortner J, Sun RL, Brennan MF, Blumgart LH. Clinical score for predicting recurrence after hepatic resection for metastatic colorectal cancer: analysis of 1001 consecutive cases. Ann Surg. 1999;230(3):309-318-321.

23. Kaplan EL, Meier P. Nonparametric estimation from incomplete observations. J Am Stat Assoc. 1958;53(282):457-81.

24. Schemper $M$, Smith TL. A note on quantifying follow-up in studies of failure time. Control Clin Trials. 1996;17:343-6.

25. Schadendorf D, Ugurel S, Schuler-Thurner B, Nestles FO, Enk A, Bröcker EB, et al. Dacarbazine (DTIC) versus vaccination with autologous peptide-pulsed dendritic cells (DC) in first-line treatment of patients with metastatic melanoma: a randomized phase III trial of the DC study group of the DeCOG. Ann Oncol. 2006;17(4):563-70.

26. Bol KF, van den Bosch T, Schreibelt G, Mensink HW, Keunen JEE, Kiliç E, et al. Adjuvant dendritic cell vaccination in high-risk Uveal melanoma. Ophthalmology. 2016;123(10):2265-7.

27. Mlecnik B, Bindea G, Angell HK, Maby P, Angelova M, Tougeron D, et al. Integrative analyses of colorectal Cancer show Immunoscore is a stronger predictor of patient survival than microsatellite instability. Immunity. 2016;44:698-711.

28. Le DT, Uram JN, Wang $H$, Bartlett BR, Kemberling $H$, Eyring AD, et al. PD-1 blockade in tumors with mismatch-repair deficiency. N Engl J Med. 2015; 372:2509-20.

29. Kim JE, Hong YS, Ryu MH, Lee JL, Chang HM, Lim SB, et al. Association between deficient mismatch repair system and efficacy to irinotecancontaining chemotherapy in metastatic colon cancer. Cancer Sci. 2011;102: 1706-11.

30. Versteven M, Van den Bergh JMJ, Marcq E, Smits ELJ, Van Tendeloo VFI, Hobo W, et al. Dendritic cells and programmed death-1 blockade: a joint venture to combat cancer. Front Immunol. 2018:9:394.

31. Forde PM, Chaft JE, Smith KN, Anagnostou V, Cottrell TR, Hellmann MD, et al. Neoadjuvant PD-1 blockade in Resectable lung Cancer. N Engl J Med. 2018;24;378(21):1976-86.
32. Melero I, Berraondo P, Rodríguez-Ruiz ME, Pérez-Gracia JL. Making the most of cancer surgery with neoadjuvant immunotherapy. Cancer Discov. 2016; 6(12):1312-4.

33. Liu J, Blake SJ, Yong MCR, Harjunpää H, Ngiow SF, Takeda K, et al. Improved efficacy of neoadjuvant compared to adjuvant immunotherapy to eradicate metastatic disease. Cancer Discov. 2016:6(12):1382-99.
Ready to submit your research? Choose BMC and benefit from:

- fast, convenient online submission

- thorough peer review by experienced researchers in your field

- rapid publication on acceptance

- support for research data, including large and complex data types

- gold Open Access which fosters wider collaboration and increased citations

- maximum visibility for your research: over $100 \mathrm{M}$ website views per year

At BMC, research is always in progress.

Learn more biomedcentral.com/submissions 